\title{
Nanoparticles and their potential for application in bone
}

This article was published in the following Dove Press journal:

International Journal of Nanomedicine

16 August 2012

Number of times this article has been viewed

\section{Andrea Tautzenberger \\ Anna Kovtun \\ Anita Ignatius}

Institute of Orthopedic Research and Biomechanics, Centre of

Musculoskeletal Research, Ulm

University, Ulm, Germany
Correspondence: Andrea Tautzenberger Helmholtzstrasse 14, 8908I

Ulm, Germany

Tel +49 73I 50055324

$\mathrm{Fax}+49$ 73I 50055302

Email andrea.tautzenberger@uni-ulm.de
Abstract: Biomaterials are commonly applied in regenerative therapy and tissue engineering in bone, and have been substantially refined in recent years. Thereby, research approaches focus more and more on nanoparticles, which have great potential for a variety of applications. Generally, nanoparticles interact distinctively with bone cells and tissue, depending on their composition, size, and shape. Therefore, detailed analyses of nanoparticle effects on cellular functions have been performed to select the most suitable candidates for supporting bone regeneration. This review will highlight potential nanoparticle applications in bone, focusing on cell labeling as well as drug and gene delivery. Labeling, eg, of mesenchymal stem cells, which display exceptional regenerative potential, makes monitoring and evaluation of cell therapy approaches possible. By including bioactive molecules in nanoparticles, locally and temporally controlled support of tissue regeneration is feasible, eg, to directly influence osteoblast differentiation or excessive osteoclast behavior. In addition, the delivery of genetic material with nanoparticulate carriers offers the possibility of overcoming certain disadvantages of standard protein delivery approaches, such as aggregation in the bloodstream during systemic therapy. Moreover, nanoparticles are already clinically applied in cancer treatment. Thus, corresponding efforts could lead to new therapeutic strategies to improve bone regeneration or to treat bone disorders.

Keywords: nanoparticles, applications, bone, cell labeling, drug delivery, gene delivery

\section{Introduction}

Biomaterials such as polymers, ceramics, and metals are widely used in bone for regenerative therapies, including in bone grafts and in tissue engineering as well as for temporary or permanent implants to stabilize fractures or replace joints. ${ }^{1}$ In recent years, biomaterials in general and bone-related implant materials in particular have been considerably refined, ${ }^{2}$ with the objective of developing functionalized materials, so-called smart materials, containing bioactive molecules to directly influence cell behavior. ${ }^{3}$

In this context, nanoparticles that are in the same size range as integral parts of natural bone, such as hydroxyapatite crystals or cellular compartments, ${ }^{4}$ are promising candidates for local applications. They form the basis of modular systems, which provide the opportunity to elicit cell responses in a spatially and temporally controlled manner by the defined release of physiologically active substances. ${ }^{5}$ Alternatively, nanoparticles can be immobilized and applied as coatings on implant surfaces or can be used for transmembrane transport for cell labeling ${ }^{6}$ or gene therapy. ${ }^{7}$ In bone, locally applied nanoparticles may be suitable for numerous potential uses with respect to the improvement of tissue regeneration, the enhanced osseointegration of implants, and the prevention of infections. 
Moreover, systemic application of nanoparticles in bone in a way analogous to cancer therapy is conceivable. However, tissue-specific targeting still represents a great challenge. Specific cell targeting of nanoparticles has been successfully developed for hyperthermia treatment of cancer ${ }^{8}$ as well as for drug delivery of paclitaxel. ${ }^{9,10}$ Similarly, nanoparticle treatment of systemic bone diseases such as osteoporosis might be feasible in the future. To date, several molecules to target bone have been identified, such as bisphosphonates and their derivatives, ${ }^{11-13}$ as well as oligopeptides targeting specifically bone-resorption ${ }^{14}$ or bone-formation surfaces. ${ }^{15}$

Summarizing, to achieve the desired effect, nanoparticles should fulfill the following criteria: they should be nontoxic for cells, ie, bioinert or biodegradable; they should effectively carry the molecule of interest, eg, labeling agent or drug; and they should exert their actions specifically on their target, without evoking side effects in other tissues. Here, the application of targeting molecules or local application of nanoparticles in the form of bioactive coatings or cements is very promising.
This review focuses on nanoparticles and their potential with regard to bone. In this field of research, no clinical trials as yet have been initiated. However, large numbers of in vitro and in vivo studies emphasize the great potential for nanoparticle applications in bone. Nanoparticles feature various modifiable facets, such as particle chemistry, functionalization, and attachment to certain surfaces. In this review, recent research approaches concerning cell labeling, drug delivery, and gene therapy to influence bone cells, as well as the interactions of different types of nanoparticles with bone cells, will be highlighted.

\section{Applications of nanoparticles in bone}

Increasingly refined nanoparticles are being developed for a wide range of applications (Figure 1). These include cell labeling to broaden research possibilities as well as to improve and noninvasively monitor cell therapy approaches. ${ }^{6}$ Moreover, drug delivery systems with improved pharmacologic characteristics are being developed. They promote enhanced therapeutic outcome by providing controlled

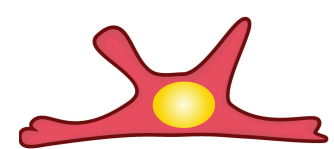

Mesenchymal stem cell

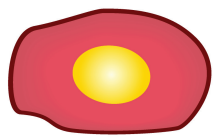

Osteoblast

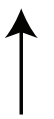

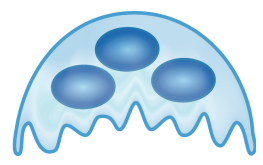

Osteoclast

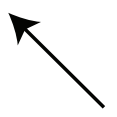

Nanoparticle applications in bone

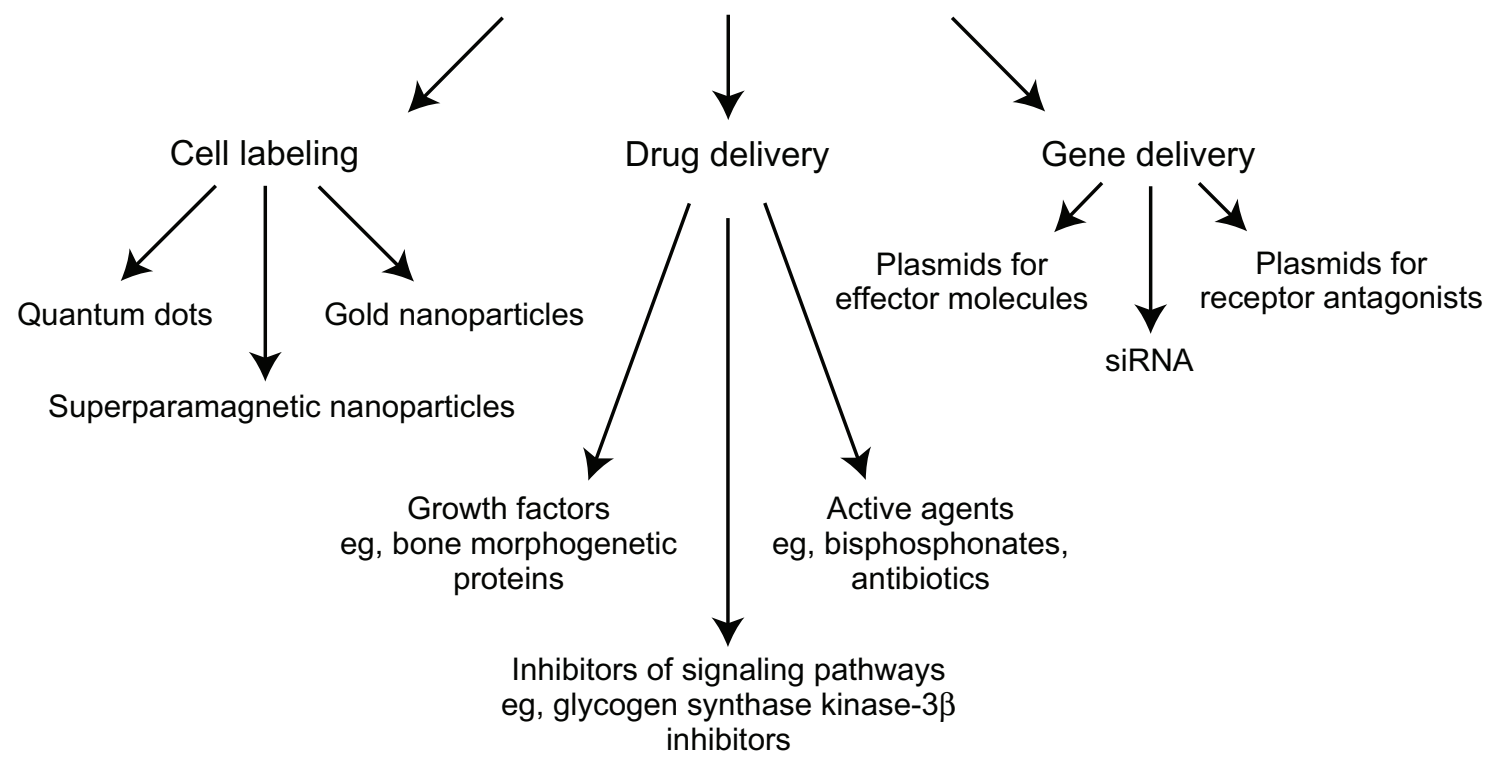

Figure I Overview of nanoparticle applications in bone, as highlighted in this review. 
release of bioactive molecules, such as growth factors or anticancer drugs. ${ }^{16}$ In addition, gene therapy concepts with good prospects are required for future treatment options based on intracellular manipulation. ${ }^{17}$ Due to the great potential for nanoparticles in the applications indicated here, these topics are discussed against the background of bone cells and tissue.

\section{Cell labeling}

Nanoparticles offer great potential for cell labeling during regenerative therapies. Depending on the therapeutic approach, labeling agents are applied in vivo or the cells are labeled ex vivo and are subsequently applied locally or systemically. Thereby, cell labeling allows for the practicable detection of transplanted cells, eg, via magnetic resonance imaging (MRI) ${ }^{18}$ Thus, cell labeling provides the opportunity to visualize and track cell transport to the area of the defect in vivo and to assess the fate and participation of the transplanted cells in tissue regeneration. This is essential for a reliable evaluation of cell therapy outcome.

Due to their exceptional regenerative potential, mesenchymal stem cells (MSCs) are thought to support tissue regeneration in stem cell therapy. The promising fields for MSC application range from promoting bone regeneration ${ }^{19,20}$ to improving fracture healing. ${ }^{21-24}$ To monitor these processes, MSCs have been labeled with diverse nanoparticles, such as quantum dots, which are small semiconductor nanocrystals, ${ }^{25,26}$ fluorescence-labeled mesoporous silica nanoparticles, ${ }^{27}$ gold nanoparticles,${ }^{28}$ or superparamagnetic iron oxide (SPIO) nanoparticles. ${ }^{29-31}$ Several types of SPIO nanoparticles have already been clinically approved for use as contrast agents in MRI, eg, of bowel or liver. ${ }^{32}$ It should be noted that bone represents a formidable target organ, which poses a particular challenge with regard to cell labeling, due to its high mineralization grade, making the visualization of labeled cells in MRI difficult.

For application as cell-labeling agents, nanoparticles need to fulfill certain criteria. On the one hand, the number of nanoparticles per cell has to be high enough to be detectable. On the other hand, this number should be low enough to avoid any interference with cellular functions. With respect to bone cells, and particularly MSCs, the particles ideally should not compromise the differentiation potential. In vitro analyses of MSC differentiation capacity in the presence of nanoparticles demonstrated the innocuousness of several SPIO nanoparticles, ${ }^{29-31,33}$ as well as of certain gold nanoparticles ${ }^{28}$ that were optimized for efficient MSC labeling and MRI visualization. As the MSC differentiation potential in vitro does not necessarily correlate with the in vivo situation, a study investigating the stemness of MSCs exposed to SPIO nanoparticles went one step further by verifying the differentiation capacity in vivo based on ossicle formation by labeled human MSCs in immunocompromised mice. ${ }^{34}$ However, depending on the experimental setting, quantum dots ${ }^{35}$ as well as SPIO nanoparticles ${ }^{36-38}$ were observed to alter osteogenic differentiation of MSCs in vitro and in vivo. For SPIO nanoparticles, the iron component was found to be one of the factors responsible for the impairment of the differentiation potential, possibly due to its increased intracellular content caused by the presence of the particles. ${ }^{36,38}$ With regard to clinical application, various SPIO nanoparticles were applied subcutaneously in mice, eg, via the incorporation of labeled MSCs in collagen scaffolds, and were demonstrated to be suitable for efficient in vivo long-term labeling and for producing convincing visualization by MRI. ${ }^{30,31}$ However, one has to keep in mind that with this technique, primarily the particles themselves are tracked and not the cells.

Further efforts are being made to expand the possibilities for detecting nanoparticle-labeled cells. For a considerable time, mostly bifunctional systems such as fluorescent, ironcontaining nanoparticles were used. ${ }^{30}$ By adding a third functionality via the incorporation of gold for the visualization of the nanoparticles through computer tomography, a refinement of cell-labeling nanoparticles could be achieved. ${ }^{39}$

As it appears, biocompatibility poses a great challenge regarding stem cell labeling due to the natural differentiation potential of the cells and essential preservation in vivo. Another issue to be addressed in the near future will be the successful applicability of cell labeling in bone, as visualization of labeled MSCs in mineralized tissue is still challenging. However, ongoing research will further improve and widen the application of nanoparticles for cell labeling, seeking the best possible way to image and track cells in musculoskeletal therapy.

\section{Drug delivery}

Due to the unsatisfactory performance of several biomaterials currently used for bone replacement or tissue engineering, improvements such as the introduction of bioactive molecules are being determinedly pursued. ${ }^{40}$ Proteins of interest can either be directly injected at the respective site or adsorbed to a biomaterial surface. In contrast to injected proteins, which are usually rapidly cleared from the body, locally adsorbed proteins are released by desorption or diffusion and may be retained longer. ${ }^{41}$ Increasingly, nanoparticles are being explored as finely adjustable delivery systems with regard 
to the location and time period of drug release. Local drug delivery is favorable in comparison with systemic application to minimize unwanted side effects. ${ }^{42}$ Moreover, adequate tuning of the nanoparticles allows for a temporally controlled, sustained delivery according to requirements. ${ }^{42,43}$ The delivery of inhibitory factors of signaling pathways has been reported as a promising tool to elucidate so far unknown pathway functions for research purposes. ${ }^{44}$ In addition, nanoparticle refinement with respect to clinical application in cancer treatment has been demonstrated by loading particles with the drug paclitaxel..$^{9,10}$

The following paragraph focuses on the use of nanoparticles as an effective protein or drug delivery system to support bone tissue regeneration. For this purpose, several nondegradable particles, such as silica, lipid, dendrimer, hydroxyapatite, or gold nanoparticles, ${ }^{43-50}$ as well as degradable particles made of poly(L-lactide $)^{51,52}$ or poly(L-lactideco-glycolide) (PLGA), ${ }^{11,42,52-56}$ have been used. Frequently, nanoparticles were combined with scaffolds such as proteinaceous hydrogels or degradable polymeric matrixes to facilitate application in bone. ${ }^{47,48,53,55,56}$

As bone contains bone-forming cells, the osteoblasts, and bone-resorbing cells, the osteoclasts, which act in concert to guarantee bone homeostasis, ${ }^{57,58}$ different strategies can be envisioned that could promote the regeneration of bone tissue. On the one hand, osteoblasts could be supported by nanoparticle-based growth factor delivery. On the other hand, osteoclast resorption could be modulated by nanoparticles locally releasing specific inhibitors.

For the enhancement of osteogenic differentiation, bone morphogenetic proteins (BMPs), members of the transforming growth factor (TGF)- $\beta$ superfamily, proved to be very suitable. Although TGF- $\beta$ itself was mainly encapsulated in nanoparticles to potentially improve cartilage regeneration, ${ }^{59-61}$ the clinically approved BMP-2 was incorporated in nanoparticles to support bone formation..$^{50-53,62}$ Biodegradable ${ }^{51,53}$ and nondegradable nanoparticles ${ }^{50,62}$ displayed sustained BMP-2 release for up to 2 weeks. Analyses of the viability of osteoblastic cells in the presence of BMP-2-loaded nanoparticles revealed that, depending on the material, cell viability could be negatively affected, thus requiring further material development. ${ }^{51,62}$ It is essential that the nanoparticles do not influence the biological activity of released growth factors so that osteogenic differentiation can be successfully supported by locally, sustainably released BMP-2. ${ }^{51,62}$ In relation to this criterion, encapsulated BMP-2 implemented into a hydrogel promoted in vivo bone remodeling in a rat calvarial critical-size defect. ${ }^{53}$ Another clinically approved member of the TGF- $\beta$ protein family, BMP-7, was investigated regarding its potential for inducing ectopic, subcutaneous bone formation in a rat model. Like BMP-2, BMP-7 encapsulated in PLGA nanospheres and immobilized in a degradable scaffold supported bone formation. ${ }^{56}$

In addition to growth factors, the extracellular matrix molecule osteopontin was incorporated in hydroxyapatite nanoparticles located in a degradable matrix and was analyzed for its osteoinductive potential in a canine endosseous gap implant model. However, other than new bone formation within the matrix, no positive effects were observed in the gap itself. ${ }^{47}$

In contrast to naturally occurring proteins, medium supplements for osteogenic differentiation in vitro, such as the synthetic glucocorticoid dexamethasone, are known to feature osteoinductive properties. ${ }^{63}$ Accordingly, dexamethasoneloaded dendrimer nanoparticles in a scaffold supported the osteogenic differentiation of rat MSCs in vitro, like free dexamethasone ${ }^{48}$ However, due to possible unwanted side effects of the drug itself in vivo, such as secondary osteoporosis, ${ }^{64}$ a clinical application appears questionable.

In addition to the manipulation of osteoblast behavior, the aforementioned second strategy of drug-loaded nanoparticle application in bone regeneration to inhibit osteoclast resorption activity has also been pursued. In a study using surface-immobilized, dexamethasonecontaining nanoparticles, their potential to decrease the number of osteoclast precursors was tested. The released dexamethasone did in fact lead to a local growth inhibition of such progenitors. ${ }^{55}$ General excessive osteoclast activity, which eventually leads to bone loss or insufficient regeneration in the case of bone defects, is often treated with bisphosphonates, a class of osteoporosis-antagonizing drugs. However, orally administered bisphosphonates display poor bioavailability (only up to $3 \%$ of the ingested amount). ${ }^{65} \mathrm{In}$ contrast, controlled, sustained delivery in the case of local bone regeneration might be feasible by using bisphosphonateloaded nanoparticles. As a model drug, alendronate was used in in vitro studies, and the inhibitory effect of the particle-associated bisphosphonate on osteoclasts (and their precursors) was confirmed for nondegradable gold nanoparticles as well as for biodegradable nanoparticles. ${ }^{46,54}$ Alendronate-modified nanoparticles were localized in the cytosol and, as expected, were observed to reduce the number of multinucleated, tartrate-resistant acid phosphatasepositive cells. ${ }^{46}$ However, based on the inhomogeneity of the osteoclast cell culture due to the differing stages of osteoclast development at a given point in time, the effects 
of encapsulated, osteoclast-influencing substances are difficult to identify. Because of the high affinity of bisphosphonates to bone, and in particular to hydroxyapatite, bisphosphonate-loaded nanoparticles could be targeted to the bone surface, which might help to specifically address and treat, for example, skeletal tumors. ${ }^{11,12}$ Additionally, bisphosphonate-loaded nanocarriers were strongly retained in mineral-comprising implants, eg, hydroxyapatite-containing scaffolds, providing the opportunity to accurately adjust the delivery system. ${ }^{49}$ Again, the chemical composition of nanoparticle constructs is of great importance to minimize potential material toxicity and to avoid cellular responses to the material itself rather than to the incorporated drug. ${ }^{11,62}$

Thus, drug delivery in bone has considerable potential. Regarding prospective progress in the area of biomaterials development, improved release kinetics of nanoparticles will contribute to an even more strictly controlled and sustained drug delivery. Moreover, the constantly increasing understanding of bone tissue in general and the regulation of osteogenic differentiation in particular will be the basis for the identification of further proteins of interest and will lead to promising alternatives besides, eg, BMP-2. In addition to the concepts discussed previously to enhance bone formation, eg, with osteoblast growth factors, or to reduce bone resorption with established drugs, such as bisphosphonates, further applications, including the nanoparticle-mediated delivery of analgesics ${ }^{42}$ or the application of bone cement comprising antibiotic-loaded nanoparticles ${ }^{43}$ will be pursued in the future.

\section{Gene delivery}

Although the therapeutic effect of many proteins is often obvious in terms of bone metabolism, the delivery of proteins of interest or growth factors still represents a great challenge due to aggregation, short lifetime in the bloodstream, and, moreover, very low efficiency due to short and abrupt release. In respect to this, the application of nanoparticles as gene carriers represents a wide and promising field, because the transfection approach potentially allows long-term expression and therefore a longer therapeutic effect.

Many proof-of-principle studies have already been performed to demonstrate that nanoparticles of an inorganic as well as an organic nature are able to deliver plasmids into bone cells. In such studies, a green fluorescent proteinencoding reporter plasmid combined with different carriers was normally used, such as calcium-doped organosilicate nanoparticles ${ }^{66}$ calcium phosphate nanoparticles, ${ }^{67}$ argininefunctionalized hydroxyapatite nanorods, ${ }^{68}$ or polymers. ${ }^{69}$
The alternative approach, an application of nanoparticles as oligonucleotide (eg, small interfering ribonucleic acid [siRNA]) carriers, was also effective in other studies, using gold, ${ }^{70}$ calcium phosphate, ${ }^{71}$ and cationic polymer/lipid TransIT-TKO ${ }^{\circledR}$ nanoparticles. ${ }^{72}$ A very promising system was developed by Zhang et $\mathrm{a}^{15}$ and consisted of siRNAloaded cationic liposomes attached to oligopeptides. Here, oligopeptide (AspSerSer ${ }_{6}$ ) provided efficient bone targeting to bone-formation surfaces, whereas siRNA that targeted casein kinase-2 interacting protein-1 promoted osteoblast activity, resulting in increased bone formation and enhanced bone microarchitecture. ${ }^{15}$

The applied studies often used a transfection approach to enhance bone regeneration in the case of fractures, delivering plasmids encoding transcription factors, growth factors, and even hormones. Studies performed in this direction described a broad range of carriers, including viral particles, ${ }^{73,74}$ folate-chitosan nanoparticles, ${ }^{75}$ PLGA nanospheres ${ }^{76}$ and nanoparticles, ${ }^{77}$ liposomes,${ }^{78}$ and even nonnanoparticulate, polymeric matrixes for the delivery of plasmid, encoding human parathyroid hormone. ${ }^{79}$

The most well-known and widely investigated proteins for bone regeneration are the BMPs, which are known to possess the greatest in vivo bone stimulatory capacity and to stimulate the differentiation of MSCs along osteoblastic and chondrogenic lineages.$^{41}$ For example, Krebs et al ${ }^{80}$ reported a gene delivery system composed of calcium phosphate nanoparticles carrying a BMP-2-encoding plasmid embedded in injectable alginate hydrogels. Hosseinkhani et al ${ }^{81}$ used polyethylenimine/DNA nanoparticles encapsulated into poly(glycolic acid) scaffolds to transfect MSCs and promote ectopic bone formation in these scaffolds in vivo.

Among other growth factors, potential stimulators of bone regeneration are vascular endothelial growth factor (VEGF) and TGF- $\beta$. It was demonstrated that adeno-associated viral vectors carrying a VEGF plasmid were able to induce neovascularization as well as bone remodeling and resorption in autografts and allografts, ${ }^{73}$ whereas retroviral VEGF transduction resulted in enhanced MSC recruitment and accelerated bone formation. ${ }^{74}$ TGF- $\beta$ was described as stimulating bone healing after injection of viral carriers functionalized with a TGF- $\beta$-encoded plasmid. ${ }^{78}$ Deng et al ${ }^{82}$ demonstrated effective gene delivery of plasmid TGF- $\beta_{1}$ to rat MSCs when combined with ethylenediamine-modified polysaccharide from mulberry leaves.

Among transcription factors, the osteoblast-specific transcriptional activator Runx2 and LIM mineralization protein-1 (named after protein domains Lin-11, Isl-1, Mec-3) 
were considered in particular because of their ability to stimulate bone formation. ${ }^{83}$

All these strategies normally include a spatial application, thus avoiding systemic toxicity and undesirable side effects. Nevertheless, in some cases the systemic application of nanoparticles (naturally in combination with desirable bone-targeting properties) is preferable, eg, in osteoporosis, arthritis, or bone tumors. Here, the combination of nanoparticles with an "osteoprotective" gene is an obvious strategy. For example, Fernandes et $\mathrm{al}^{75}$ used folate-chitosan nanoparticles in combination with an interleukin-1 receptor antagonist (IL-1Ra) gene to decrease inflammation and reverse alterations in bone turnover in an arthritic rat model.

Such a protective effect could also be achieved via the introduction of tumor inhibitors, eg, IL-18 ${ }^{84}$ Cytokine IL-18 is normally described as a T-cell and NK-cell activator and was previously shown to inhibit sarcoma growth via activation of the immune response and antiangiogenic activity in vivo. Nie et $\mathrm{al}^{84}$ observed the inhibition of tumorigenesis in mice after the application of polymeric monomethoxy poly(ethylene glycol) (PEG)-PLGA-PEG nanoparticles complexed with IL-18 plasmid.

The alternative approach is to downregulate factors that enhance tumor formation. It is known that a certain expression profile in some tumors, eg, mammary carcinoma, is associated with metastases formation in the skeleton. With respect to this, Elazar et $\mathrm{al}^{85}$ demonstrated that silencing of osteopontin and bone sialoprotein, which belong to the "abnormal" expression set described previously, with siRNAfunctionalized PLGA nanoparticles led to the inhibition of metastatic bone lysis.

Thus, nanoparticle-based gene therapy offers great opportunities for fine modulation and treatment of bone diseases of different origin - from fractures to malignant tumors. Various possibilities for the delivery of enhancing as well as inhibitory genetic material have been explored over the past years, and several disadvantages of protein delivery, such as inadequate release kinetics, might be overcome by gene delivery approaches. Thereby, polymeric and inorganic nanoparticles represent a more promising field than viral vectors, due to their safety, degradability, and possible surface modifications, allowing nanoparticle targeting to cells of interest. The major advantages are potentially easy spatial application of particles (in terms of implants, cements, or direct bone injections), which minimizes systemic toxicity and potential side effects, and a prolonged therapeutic effect compared with pure proteins, thus making gene therapy a very promising strategy for the future.

\section{Interactions of nanoparticles with bone cells}

During bone regeneration, bone cells such as MSCs, which can differentiate into bone-forming osteoblasts, osteoblasts themselves, and bone-resorbing osteoclasts, ${ }^{57,58}$ tightly interact to ensure successful tissue reconstruction. Accordingly, it is important not to disturb such regenerative processes, eg, by eliciting undesired inflammatory responses induced by nanoparticles. Therefore, investigations on possible particle uptake as well as on the potential effects of nanoparticles on bone cell functions, such as limitation of MSC differentiation potential, bone mineralization by osteoblasts, or modulation of osteoclastic resorption activity, are required prior to any nanoparticle application in the field of bone research. Thus, the interactions of bone cells with diverse nanoparticles are discussed here.

\section{Mesenchymal stem cells}

MSCs are multipotent cells, which can be isolated, for example, from bone marrow. MSCs feature in vitro plastic adherence and can be characterized by the expression of a defined set of surface markers as well as by their differentiation potential into mesenchymal tissue lineages such as bone, cartilage, or adipose tissue ${ }^{86,87}$ In contrast to osteoclasts, which are known to phagocytize particles due to their relationship to monocytes/macrophages, ${ }^{88} \mathrm{MSCs}$ do not necessarily take up particles effectively.

With respect to the cellular internalization of nanoparticles or foreign material in general, the uptake behavior depends on the cell type, particle chemistry, charge, and shape, as well as particle carrier systems and cellular microenvironment. Therefore, it is difficult to deduce universally valid rules for the prediction of particle uptake. In terms of charge, positively charged substances such as poly(L-lysine) generally promote the internalization of genetic material. ${ }^{89}$ Equally, positive charges on the surface of polymeric nanoparticles were found to be beneficial for particle uptake by MSCs..$^{90,91}$ Negatively charged polymeric nanoparticles such as carboxyl- or phosphonate-functionalized particles were also readily internalized by MSCs. ${ }^{92,93}$ These observations suggest specific interactions of both, positive and negative functional groups, with the cell surface. Most of the particles were then localized in the cytosol, often in membrane-enclosed clusters. ${ }^{91,93}$ For up to 3 weeks in long-term culture, these particles did not hamper the viability of undifferentiated and differentiated MSCs. ${ }^{91,93}$ With regard to differing particle chemistry, metallic silver nanoparticles, too, were taken up into endolysosomal structures in the cytosol. ${ }^{94}$ Although certain 
silver nanoparticles did not compromise MSC viability, ${ }^{94}$ others of approximately the same size caused serious DNA damage even at lower concentrations in a different study. ${ }^{95}$ In addition to polymeric and metallic nanoparticles, quantum dots of just a few nanometers play an important role in MSC research, based on their excellent cell-labeling qualities. ${ }^{25}$ Quantum dots, either unfunctionalized or provided with, eg, arginine-glycine-aspartic acid peptides, were spontaneously taken up by MSCs and could be detected inside the cells over a period of 3 weeks. . $^{35,96}$

With respect to the mechanisms for nanoparticle uptake, cells can rely on diverse endocytotic internalization pathways such as clathrin- or caveolae-mediated endocytosis and macropinocytosis. ${ }^{97}$ Studies with specific inhibitors for the different uptake routes revealed a heterogeneous picture. Although polymeric and metallic particles were in part taken up via the clathrin-mediated pathway, ${ }^{90,92,94}$ macropinocytosis was also involved to some extent. ${ }^{94}$

Following the elucidation of nanoparticle uptake and the underlying mechanisms, the analysis of potential influences on MSC characteristics and function is essential. Again, the literature is quite heterogeneous on this topic, and nanoparticles of different chemical nature and shape will be considered here.

Calcium phosphate nanoparticles present an interesting alternative when attempting to imitate bone structure and function with regard to the in vivo crystallinity of calcium phosphates. ${ }^{98}$ MSC proliferation was affected in a sizedependent manner by the exposure of these cells to calcium phosphate nanoparticles, with larger particles being more harmful. ${ }^{99}$ The same research group further investigated a potential dependency on particle concentration and their form of appearance. It was observed that with increasing concentration as well as with amorphous particles in contrast to crystalline calcium phosphate particles, osteogenic cell differentiation and matrix mineralization decreased. ${ }^{100,101}$

Likewise, metallic particles, eg, commercially pure titanium nanoparticles, decreased adhesion and suppressed MSC differentiation. ${ }^{102}$ In contrast, other metallic particles, such as gold nanotracers, did not affect MSC differentiation into the osteogenic and adipogenic lineages. ${ }^{28}$

Similarly, polymeric phosphonate-functionalized particles, which exhibited excellent binding properties to metallic surfaces such as titanium dioxide, ${ }^{103}$ were investigated with regard to their effect on MSC differentiation. Qualitative characteristic staining as well as comprehensive quantitative analyses of marker gene expression for the osteogenic, adipogenic, and chondrogenic lineages revealed no detrimental effect arising from the phosphonate-functionalized particles. ${ }^{93}$

The MSC differentiation potential was investigated in the presence of various other particle types. Quantum dots, eg, consisting of $\mathrm{CdSe} / \mathrm{ZnS}$, restrained osteogenic differentiation in terms of alkaline phosphatase activity as well as osteopontin and osteocalcin expression. ${ }^{35}$ In contrast, arginineglycine-aspartic acid-conjugated quantum dots did not affect the differentiation potential, as assessed by characteristic staining for the osteogenic, adipogenic, and chondrogenic lineages,${ }^{96}$ and thus might be better suited with regard to biocompatibility with MSCs. Equally, mesoporous silica nanoparticles, either functionalized with different amounts of positively charged functional groups or with gadolinium, did not influence MSC differentiation, as confirmed by qualitative analyses after short-term exposure. ${ }^{104,105}$

In addition to the effects on the differentiation potential, further MSC functions can be modulated by nanoparticles. Ferucarbotran particles with superparamagnetic properties were efficiently taken up by MSCs. ${ }^{106}$ Due to the intrinsic peroxidase-like activity of such magnetic nanoparticles, ${ }^{107}$ ferucarbotran particles stimulated MSC growth through a reduction in intracellular hydrogen peroxide. ${ }^{108}$

Thus, the heterogeneous picture of research on the interactions of nanoparticles with MSCs makes it difficult to draw general conclusions. However, it becomes clear that parameters such as chemistry, size, and shape in some cases greatly affect the particle uptake behavior of MSCs as well as their natural differentiation potential. Thus, it will be necessary to continue the thorough verification of nanoparticle innocuousness independent of their characteristics to ensure unaffected MSC differentiation.

\section{Osteoblasts}

Osteoblasts are bone-forming cells with the ability to mineralize and continuously remodel bone. ${ }^{57}$ Additionally, osteoblasts make an essential contribution to the regulation of osteoclast activity and thus to bone homoeostasis by secreting the osteoclast-regulating factors macrophage colony-stimulating factor (M-CSF), receptor activator of nuclear factor $\mathrm{\kappa B}$ ligand (RANKL), and its decoy receptor osteoprotegerin. ${ }^{57,58}$ Therefore, nanoparticles exerting effects on osteoblasts might, in addition, indirectly influence osteoclasts.

Similar to MSCs, osteoblasts were demonstrated to internalize a variety of nanoparticles, such as wear debris, ${ }^{109}$ quantum dot/hydroxyapatite composites, ${ }^{110}$ calcium phosphate nanoshells, ${ }^{111}$ and polymeric particles. ${ }^{112}$ Again, various factors influenced nanoparticle uptake and potential cellular effects. 
With regard to the particle charge, the internalization of positively charged nanoparticles is generally facilitated. In line with this observation, positive surface groups appeared to enhance internalization by osteoblastic cells when comparing negatively and positively charged hydroxyapatite nanoparticles or mesoporous silica nanoparticles with increasing positive charge. ${ }^{104,113}$ However, studies with negatively charged phosphonate-functionalized nanoparticles indicated that these particles, too, were taken up by osteoblasts. ${ }^{112}$

In addition to particle charge, shape plays an important role. Normally, spherical nanoparticles are readily internalized and do not impede cell functions. In accordance with this general observation, spherical zinc oxide nanoparticles were not cytotoxic for osteoblastic cells, in contrast to rod-shaped particles of the same material. ${ }^{114}$ However, needle-shaped as well as spherical hydroxyapatite nanoparticles decreased osteoblast cell numbers in a different study. ${ }^{115}$

With respect to nanoparticle size, the findings again diverged. On the one hand, hydroxyapatite and titania nanoparticles of up to $40 \mathrm{~nm}$ diameter decreased osteoblastic cell proliferation and viability, respectively. ${ }^{99,116}$ On the other hand, in another study, only hydroxyapatite nanoparticles with a diameter of $20 \mathrm{~nm}$ enhanced cell growth of osteoblast-like cells compared with larger particles with a diameter of $80 \mathrm{~nm} \cdot{ }^{117}$

In addition to particle uptake by osteoblasts and potential effects on proliferation and viability, the consequences of nanoparticle presence on the differentiation and mineralization of osteoblastic cells were assessed in a variety of studies with a wide range of particles. The expression of alkaline phosphatase, a marker for osteoblast differentiation, ${ }^{118}$ was found to be reduced by the addition of titanium and silver nanoparticles, ${ }^{109,119}$ whereas alkaline phosphatase activity and collagen type I synthesis, as well as calcium deposition and mineralization, were increased in the presence of calcium phosphate nanoshells, hydroxyapatite-coated iron oxide particles, strontium-doped hydroxyapatite nanocrystal surfaces, and nanostructured zinc oxide and titania in a different experimental series. ${ }^{11,120-122}$ These collected findings imply the involvement of complex mechanisms in the internalization of differently composed nanoparticles and in the evocation of variable osteoblast responses.

As osteoblasts secrete factors that regulate osteoclastogenesis, ${ }^{58}$ the expression of RANKL, M-CSF, and osteoprotegerin was analyzed following incubation with various nanoparticles. A catabolic phenotype was induced by polyethylene particles through alteration of the RANKL/ osteoprotegerin ratio. ${ }^{123}$ Similar osteoclastogenic effects were triggered in osteoblastic cells by titania nanoparticles via increased gene expression of granulocyte colony-stimulating factor. ${ }^{116}$ In contrast, phosphonate-functionalized nanoparticles did not affect the expression of osteoclast-regulating genes in primary human osteoblasts. ${ }^{12}$

Further examined effects of nanoparticles on osteoblasts comprised DNA damage, confirmed for hydroxyapatite nanoparticles in osteoblastic cells, ${ }^{115}$ and titania particles in various murine organs, including bone marrow. ${ }^{124}$ Furthermore, a possible improvement in implant fixation by applying nanoparticle coatings was investigated. Contrary to expectations, calcium phosphate nanoparticle coatings did not enhance the osseointegration of implants in vivo. ${ }^{125}$ In contrast, titanium implants coated with a composite of hydroxyapatite nanoparticles and poly(D,L-lactide) improved the osseointegration in terms of new bone formation and mechanical fixation in sheep compared with implants without hydroxyapatite nanoparticles. ${ }^{126}$

In summary, the number of publications on current research regarding the interactions of nanoparticles with osteoblasts appears manageable. Still, findings with regard to nanoparticle influence on differentiation and mineralization of osteoblasts clearly diverge, depending on particle characteristics. As osteoblast behavior is closely connected to osteoclast formation and activity, it will be important to generally extend respective analyses to factors such as RANKL, which affect bone homeostasis in general, in order to ensure covering different fields of potential nanoparticle influence.

\section{Osteoclasts}

Osteoclasts, bone-resorbing cells, are derived from hematopoietic precursor cells and are closely related to macrophages. ${ }^{127}$ Because macrophages are known to activate the immune response by phagocytizing pathogens, ${ }^{128}$ it is no surprise that osteoclasts, too, are capable of phagocytizing foreign matter such as biomaterial particles. ${ }^{88}$ Osteoclasts are part of a complex network coordinating bone homeostasis and regenerative processes, eg, in the case of bone defects. In this regard, the osseointegration of bone substitutes as well as a favored bone formation is highly desired. Osteoclasts, like MSCs and osteoblasts, play a decisive role in fracture healing. ${ }^{129}$ If disadvantageously influenced, eg, by metallic wear particles of implants used for fracture stabilization, ${ }^{130,131}$ excessive osteoclast activation frequently causes aseptic loosening of implants. ${ }^{132}$ Thus, locally applied (drug-loaded) nanoparticles might favorably modulate osteoclast resorption. However, due 
to the potential for affected osteoclast activity as a result of contact with foreign matter itself, it is a prerequisite to investigate the basic interactions of osteoclasts with nanoparticles.

In fact, diverse nanoparticles were readily taken up by undifferentiated monocytes and differentiated osteoclasts. ${ }^{94,112}$ However, differing subsets of monocytes, eg, those involved in chronic disease and in tissue repair, respectively, differentially incorporated nanoparticles, ${ }^{133}$ implying a whole set of parameters influencing nanoparticle uptake in osteoclastic cells. With respect to the intracellular localization of nanoparticles, varying observations were made. Although metallic and polymeric nanoparticles were localized in the cytoplasm, partly surrounded by membrane-like structures, ${ }^{94,112}$ hydroxyapatite nanoparticles were detected within specialized cellular cavities with a connection to the extracellular environment, the so-called surface-connected compartments. ${ }^{134}$ The uptake of various nanoparticles may lead to changes in osteoclast morphology, eg, a less pronounced ruffled border and modulation of cell proliferation, ${ }^{120}$ as well as interference with osteoclast formation and resorption activity. An established characteristic to assess the formation of osteoclasts is the number of tartrate-resistant acid phosphatase-positive, multinucleated cells that are generated in vitro. ${ }^{135}$ Based on the analysis of this feature, diverse metallic and silica nanoparticles negatively influenced osteoclast formation. ${ }^{11,136-138}$ In contrast, other particles did not compromise the formation of multinucleated cells ${ }^{112,139}$ or even promoted osteoclast maturation. ${ }^{140}$ Similarly, the influence of nanoparticles on osteoclast resorption activity is heterogeneous. Although the resorption activity of undifferentiated monocytes and osteoclasts could be enhanced by metal ions or nanoparticles, ${ }^{141,142}$ other types of particles did not necessarily modulate resorption. ${ }^{112}$ In addition to the effects that nanoparticles exert on osteoclast function, inflammatory responses can be induced by nanoparticles, eg, in implant wear, which, in turn, may affect osteoclasts. ${ }^{140,143}$ Osteoclast precursors themselves, too, were observed to react to titanium alloy and SPIO nanoparticles with increased cytokine production. ${ }^{144,145}$ However, the exposure of osteoclasts and their precursors to nanoparticles does not coercively lead to an upregulation of inflammatory factors in these cells. ${ }^{66,112}$ In addition to potential inflammation, further severe effects such as DNA damage or initiation of apoptosis can be elicited by nanoparticles in osteoclast precursors. ${ }^{116,146}$

In short, osteoclasts originate from the same precursors as other phagocytizing cells, such as macrophages, and readily take up nanoparticles. Arising clinical issues include aseptic implant loosening due to excessive osteoclast activity potentially caused by implant wear in the form of particles. However, only a few studies actually investigated osteoclast resorption activity, even though this osteoclast feature is crucial for eventual changes in bone mass. In general, nanoparticles stimulated osteoclasts. Thus, a careful selection of promising candidates for continuing research is essential.

\section{Conclusion}

Nanoparticles represent a promising tool for research purposes as well as for therapeutic approaches in bone. These could be finely modified, taking into account that the type of interaction between nanoparticle and cell varies depending on nanoparticle composition. Initial studies confirmed the innocuousness of several nanoparticles with respect to MSC differentiation potential and osteoclast function. Thus, different strategies for nanoparticle application in bone (eg, as cell-labeling agents and for drug or gene delivery) have great potential for monitoring and supporting tissue regeneration. In other areas, such as cancer treatment, nanoparticles already contribute to successful clinical approaches, and similar efforts to use nanoparticulate systems to promote bone regeneration will gradually lead to therapeutic success here as well.

\section{Disclosure}

The authors report no conflicts of interest in this work.

\section{References}

1. Navarro M, Michiardi A, Castano O, Planell JA. Biomaterials in orthopaedics. J R Soc Interface. 2008;5(27):1137-1158.

2. Huebsch N, Mooney DJ. Inspiration and application in the evolution of biomaterials. Nature. 2009;462(7272):426-432.

3. Mieszawska AJ, Kaplan DL. Smart biomaterials - regulating cell behavior through signaling molecules. BMC Biol. 2010;8:59.

4. Webster TJ, Ahn ES. Nanostructured biomaterials for tissue engineering bone. Adv Biochem Eng Biotechnol. 2006;103:275-308.

5. Biondi M, Ungaro F, Quaglia F, Netti PA. Controlled drug delivery in tissue engineering. Adv Drug Deliv Rev. 2008;60(2):229-242.

6. Bhirde A, Xie J, Swierczewska M, Chen X. Nanoparticles for cell labeling. Nanoscale. 2011;3(1):142-153.

7. Panyam J, Labhasetwar V. Biodegradable nanoparticles for drug and gene delivery to cells and tissue. Adv Drug Deliv Rev. 2003;55(3): 329-347.

8. Dutz S, Kettering M, Hilger I, Muller R, Zeisberger M. Magnetic multicore nanoparticles for hyperthermia - influence of particle immobilization in tumour tissue on magnetic properties. Nanotechnology. 2011;22(26):265102.

9. Gradishar WJ, Tjulandin S, Davidson N, et al. Phase III trial of nanoparticle albumin-bound paclitaxel compared with polyethylated castor oil-based paclitaxel in women with breast cancer. $J$ Clin Oncol. 2005;23(31):7794-7803.

10. Mirtsching B, Cosgriff T, Harker G, Keaton M, Chidiac T, Min M. A phase II study of weekly nanoparticle albumin-bound paclitaxel with or without trastuzumab in metastatic breast cancer. Clin Breast Cancer. 2011;11(2):121-128. 
11. Cenni E, Avnet S, Granchi D, et al. The effect of poly(D,L-lactideco-glycolide)-alendronate conjugate nanoparticles on human osteoclast precursors. J Biomater Sci Polym Ed. July 20, 2011. [Epub ahead of print.]

12. Salerno M, Cenni E, Fotia C, et al. Bone-targeted doxorubicin-loaded nanoparticles as a tool for the treatment of skeletal metastases. Curr Cancer Drug Targets. 2010;10(7):649-659.

13. Yewle JN, Puleo DA, Bachas LG. Enhanced affinity bifunctional bisphosphonates for targeted delivery of therapeutic agents to bone. Bioconjug Chem. 2011;22(12):2496-2506.

14. Wang D, Miller SC, Shlyakhtenko LS, et al. Osteotropic peptide that differentiates functional domains of the skeleton. Bioconjug Chem. 2007;18(5):1375-1378

15. Zhang G, Guo B, Wu H, et al. A delivery system targeting bone formation surfaces to facilitate RNAi-based anabolic therapy. Nat Med. 2012;18(2):307-314.

16. Allen TM, Cullis PR. Drug delivery systems: entering the mainstream. Science. 2004;303(5665):1818-1822.

17. Evans C. Gene therapy for the regeneration of bone. Injury. 2011;42(6): 599-604.

18. Edelman RR, Warach S. Magnetic resonance imaging (1). $N$ Engl J Med. 1993;328(10):708-716.

19. Bruder SP, Fink DJ, Caplan AI. Mesenchymal stem cells in bone development, bone repair, and skeletal regeneration therapy. J Cell Biochem. 1994;56(3):283-294.

20. Bianco P, Riminucci M, Gronthos S, Robey PG. Bone marrow stromal stem cells: nature, biology, and potential applications. Stem Cells. 2001;19(3):180-192.

21. Granero-Molto F, Myers TJ, Weis JA, et al. Mesenchymal stem cells expressing insulin-like growth factor-I (MSCIGF) promote fracture healing and restore new bone formation in Irs 1 knockout mice: analyses of MSCIGF autocrine and paracrine regenerative effects. Stem Cells. 2011;29(10):1537-1548.

22. Granero-Molto F, Weis JA, Miga MI, et al. Regenerative effects of transplanted mesenchymal stem cells in fracture healing. Stem Cells. 2009;27(8):1887-1898.

23. Lee SW, Padmanabhan P, Ray P, et al. Stem cell-mediated accelerated bone healing observed with in vivo molecular and small animal imaging technologies in a model of skeletal injury. J Orthop Res. 2009;27(3):295-302.

24. Tseng SS, Lee MA, Reddi AH. Nonunions and the potential of stem cells in fracture-healing. J Bone Joint Surg Am. 2008;90 Suppl 1: 92-98.

25. Byers RJ, Hitchman ER. Quantum dots brighten biological imaging. Prog Histochem Cytochem. 2011;45(4):201-237.

26. Muller-Borer BJ, Collins MC, Gunst PR, Cascio WE, Kypson AP. Quantum dot labeling of mesenchymal stem cells. J Nanobiotechnology. 2007;5:9.

27. Huang DM, Hung Y, Ko BS, et al. Highly efficient cellular labeling of mesoporous nanoparticles in human mesenchymal stem cells: implication for stem cell tracking. Faseb J. 2005;19(14): 2014-2016.

28. Ricles LM, Nam SY, Sokolov K, Emelianov SY, Suggs LJ. Function of mesenchymal stem cells following loading of gold nanotracers. Int J Nanomedicine. 2011;6:407-416.

29. Jasmin, Torres AL, Nunes HM, et al. Optimized labeling of bone marrow mesenchymal cells with superparamagnetic iron oxide nanoparticles and in vivo visualization by magnetic resonance imaging. J Nanobiotechnology. 2011;9:4.

30. Lu CW, Hung Y, Hsiao JK, et al. Bifunctional magnetic silica nanoparticles for highly efficient human stem cell labeling. Nano Lett. 2007;7(1):149-154.

31. Schmidtke-Schrezenmeier G, Urban M, Musyanovych A, et al. Labeling of mesenchymal stromal cells with iron oxide-poly(L-lactide) nanoparticles for magnetic resonance imaging: uptake, persistence, effects on cellular function and magnetic resonance imaging properties. Cytotherapy. 2011;13(8):962-975.
32. Wang YX, Hussain SM, Krestin GP. Superparamagnetic iron oxide contrast agents: physicochemical characteristics and applications in MR imaging. Eur Radiol. 2001;11(11):2319-2331.

33. Arbab AS, Yocum GT, Rad AM, et al. Labeling of cells with ferumoxides-protamine sulfate complexes does not inhibit function or differentiation capacity of hematopoietic or mesenchymal stem cells. NMR Biomed. 2005;18(8):553-559.

34. Balakumaran A, Pawelczyk E, Ren J, et al. Superparamagnetic iron oxide nanoparticles labeling of bone marrow stromal (mesenchymal) cells does not affect their "stemness". PLoS One. 2010;5(7):e11462.

35. Hsieh SC, Wang FF, Lin CS, Chen YJ, Hung SC, Wang YJ. The inhibition of osteogenesis with human bone marrow mesenchymal stem cells by $\mathrm{CdSe} / \mathrm{ZnS}$ quantum dot labels. Biomaterials. 2006;27(8): 1656-1664.

36. Chen YC, Hsiao JK, Liu HM, et al. The inhibitory effect of superparamagnetic iron oxide nanoparticle (Ferucarbotran) on osteogenic differentiation and its signaling mechanism in human mesenchymal stem cells. Toxicol Appl Pharmacol. 2010;245(2):272-279.

37. Farrell E, Wielopolski P, Pavljasevic P, et al. Effects of iron oxide incorporation for long term cell tracking on MSC differentiation in vitro and in vivo. Biochem Biophys Res Commun. 2008;369(4):1076-1081.

38. Pawelczyk E, Arbab AS, Pandit S, Hu E, Frank JA. Expression of transferrin receptor and ferritin following ferumoxides-protamine sulfate labeling of cells: implications for cellular magnetic resonance imaging. NMR Biomed. 2006;19(5):581-592.

39. van Schooneveld MM, Cormode DP, Koole R, et al. A fluorescent, paramagnetic and PEGylated gold/silica nanoparticle for MRI, CT and fluorescence imaging. Contrast Media Mol Imaging. 2010;5:231-236.

40. Laurencin CT, Ambrosio AM, Borden MD, Cooper JA Jr. Tissue engineering: orthopedic applications. Annu Rev Biomed Eng. 1999;1: $19-46$.

41. Kofron MD, Li X, Laurencin CT. Protein- and gene-based tissue engineering in bone repair. Curr Opin Biotechnol. 2004;15(5):399-405.

42. Kim YT, Caldwell JM, Bellamkonda RV. Nanoparticle-mediated local delivery of methylprednisolone after spinal cord injury. Biomaterials. 2009;30(13):2582-2590.

43. Shen SC, Ng WK, Shi Z, Chia L, Neoh KG, Tan RB. Mesoporous silica nanoparticle-functionalized poly(methyl methacrylate)-based bone cement for effective antibiotics delivery. J Mater Sci Mater Med. 2011;22(10):2283-2292.

44. Shah DA, Kwon SJ, Bale SS, Banerjee A, Dordick JS, Kane RS. Regulation of stem cell signaling by nanoparticle-mediated intracellular protein delivery. Biomaterials. 2011;32(12):3210-3219.

45. Chi B, Park SJ, Park MH, Lee SY, Jeong B. Oligopeptide delivery carrier for osteoclast precursors. Bioconjug Chem. 2010;21(8): $1473-1478$.

46. Fanord F, Fairbairn K, Kim H, Garces A, Bhethanabotla V, Gupta VK. Bisphosphonate-modified gold nanoparticles: a useful vehicle to study the treatment of osteonecrosis of the femoral head. Nanotechnology. 2011;22(3):035102.

47. Jensen T, Baas J, Dolathshahi-Pirouz A, et al. Osteopontin functionalization of hydroxyapatite nanoparticles in a PDLLA matrix promotes bone formation. J Biomed Mater Res A. 2011;99(1):94-101.

48. Oliveira JM, Sousa RA, Kotobuki N, et al. The osteogenic differentiation of rat bone marrow stromal cells cultured with dexamethasone-loaded carboxymethylchitosan/poly(amidoamine) dendrimer nanoparticles. Biomaterials. 2009;30(5):804-813.

49. Wang G, Mostafa NZ, Incani V, Kucharski C, Uludag H. Bisphosphonatedecorated lipid nanoparticles designed as drug carriers for bone diseases. J Biomed Mater Res A. 2012;100(3):684-693.

50. Xie G, Sun J, Zhong G, Liu C, Wei J. Hydroxyapatite nanoparticles as a controlled-release carrier of BMP-2: absorption and release kinetics in vitro. J Mater Sci Mater Med. 2010;21(6):1875-1880.

51. Chen L, Liu L, Li C, Tan Y, Zhang G. A new growth factor controlled drug release system to promote healing of bone fractures: nanospheres of recombinant human bone morphogenetic- 2 and polylactic acid. J Nanosci Nanotechnol. 2011;11(4):3107-3114. 
52. Mercado AE, Ma J, He X, Jabbari E. Release characteristics and osteogenic activity of recombinant human bone morphogenetic protein-2 grafted to novel self-assembled poly(lactide-co-glycolide fumarate) nanoparticles. J Control Release. 2009;140(2):148-156.

53. Chung YI, Ahn KM, Jeon SH, Lee SY, Lee JH, Tae G. Enhanced bone regeneration with BMP-2 loaded functional nanoparticle-hydrogel complex. J Control Release. 2007;121(1-2):91-99.

54. Cohen-Sela E, Chorny M, Koroukhov N, Danenberg HD, Golomb G. A new double emulsion solvent diffusion technique for encapsulating hydrophilic molecules in PLGA nanoparticles. J Control Release. 2009;133(2):90-95.

55. Lo CT, Van Tassel PR, Saltzman WM. Biodegradable poly(lactideco-glycolide) nanoparticle assembly for continuous release of bioactive agents from medical devices. Biomaterials. 2010;31(13): 3631-3642.

56. Wei W, Zeve D, Suh JM, et al. Biphasic and dosage-dependent regulation of osteoclastogenesis by beta-catenin. Mol Cell Biol. 2011; 31(23):4706-4719.

57. Neve A, Corrado A, Cantatore FP. Osteoblast physiology in normal and pathological conditions. Cell Tissue Res. 2011;343(2):289-302.

58. Teitelbaum SL. Bone resorption by osteoclasts. Science. 2000; 289(5484):1504-1508.

59. Lim SM, Oh SH, Lee HH, Yuk SH, Im GI, Lee JH. Dual growth factorreleasing nanoparticle/hydrogel system for cartilage tissue engineering J Mater Sci Mater Med. 2010;21(9):2593-2600.

60. Park JS, Park K, Woo DG, Yang HN, Chung HM, Park KH. PLGA microsphere construct coated with TGF-beta 3 loaded nanoparticles for neocartilage formation. Biomacromolecules. 2008;9(8):2162-2169.

61. Park JS, Yang HN, Woo DG, Chung HM, Park KH. In vitro and in vivo chondrogenesis of rabbit bone marrow-derived stromal cells in fibrin matrix mixed with growth factor loaded in nanoparticles. Tissue Eng Part A. 2009;15(8):2163-2175.

62. Zhang S, Wang G, Lin X, et al. Polyethylenimine-coated albumin nanoparticles for BMP-2 delivery. Biotechnol Prog. 2008;24(4): 945-956.

63. Cheng SL, Yang JW, Rifas L, Zhang SF, Avioli LV. Differentiation of human bone marrow osteogenic stromal cells in vitro: induction of the osteoblast phenotype by dexamethasone. Endocrinology. 1994; 134(1):277-286.

64. den Uyl D, Bultink IE, Lems WF. Glucocorticoid-induced osteoporosis. Clin Exp Rheumatol. 2011;29(5 Suppl 68):S93-S98.

65. Delmas PD. Treatment of postmenopausal osteoporosis. Lancet. 2002; 359(9322):2018-2026

66. Müller K, Skepper JN, Posfai M, et al. Effect of ultrasmall superparamagnetic iron oxide nanoparticles (Ferumoxtran-10) on human monocytemacrophages in vitro. Biomaterials. 2007;28(9):1629-1642.

67. Klesing J, Chernousova S, Epple M. Freeze-dried cationic calcium phosphate nanorods as versatile carriers of nucleic acids (DNA, siRNA) J Mater Chem. 2012;22:199-204.

68. Gonzalez-McQuire R, Green DW, Partridge KA, Oreffo ROC, Mann S, Davis SA. Coating of human mesenchymal cells in 3D culture with bioinorganic nanoparticles promotes osteoblastic differentiation and gene transfection. Adv Mater. 2007;19(17):2236-2240.

69. Harris TJ, Green JJ, Fung PW, Langer R, Anderson DG, Bhatia SN. Tissue-specific gene delivery via nanoparticle coating. Biomaterials. 2010;31(5):998-1006.

70. Jen CP, Chen YH, Fan CS, et al. A nonviral transfection approach in vitro: the design of a gold nanoparticle vector joint with microelectromechanical systems. Langmuir. 2004;20(4):1369-1374.

71. Zhang X, Kovtun A, Mendoza-Palomares C, et al. SiRNA-loaded multi-shell nanoparticles incorporated into a multilayered film as a reservoir for gene silencing. Biomaterials. 2010;31(23): 6013-6018.

72. Andersen MØ, Nygaard JV, Burns JS, et al. siRNA nanoparticle functionalization of nanostructured scaffolds enables controlled multilineage differentiation of stem cells. Mol Ther. 2010;18(11): 2018-2027.
73. Ito $\mathrm{H}$, Koefoed M, Tiyapatanaputi $\mathrm{P}$, et al. Remodeling of cortical bone allografts mediated by adherent rAAV-RANKL and VEGF gene therapy. Nat Med. 2005;11(3):291-297.

74. Peng H, Wright V, Usas A, et al. Synergistic enhancement of bone formation and healing by stem cell-expressed VEGF and bone morphogenetic protein-4. J Clin Invest. 2002;110(6):751-759.

75. Fernandes JC, Wang H, Jreyssaty C, et al. Bone-protective effects of nonviral gene therapy with folate-chitosan DNA nanoparticle containing interleukin-1 receptor antagonist gene in rats with adjuvant-induced arthritis. Mol Ther. 2008;16(7):1243-1251.

76. Labhasetwar V, Bonadio J, Goldstein SA, Levy RJ. Gene transfection using biodegradable nanospheres: results in tissue culture and a rat osteotomy model. Colloids Surf B Biointerfaces. 1999;16:281-290.

77. Kim JH, Park JS, Yang HN, et al. The use of biodegradable PLGA nanoparticles to mediate SOX9 gene delivery in human mesenchymal stem cells (hMSCs) and induce chondrogenesis. Biomaterials. 2011;32(1):268-278.

78. Kofron MD, Laurencin CT. Orthopaedic applications of gene therapy. Curr Gene Ther. 2005;5(1):37-61.

79. Bonadio J, Smiley E, Patil P, Goldstein S. Localized, direct plasmid gene delivery in vivo: prolonged therapy results in reproducible tissue regeneration. Nat Med. 1999;5(7):753-759.

80. Krebs MD, Salter E, Chen E, Sutter KA, Alsberg E. Calcium phosphateDNA nanoparticle gene delivery from alginate hydrogels induces in vivo osteogenesis. J Biomed Mater Res A. 2010;92(3):1131-1138.

81. Hosseinkhani H, Hosseinkhani M, Gabrielson NP, Pack DW, Khademhosseini A, Kobayashi H. DNA nanoparticles encapsulated in 3D tissue-engineered scaffolds enhance osteogenic differentiation of mesenchymal stem cells. J Biomed Mater Res A. 2008;85(1):47-60.

82. Deng W-W, Cao X, Wang M, et al. Efficient gene delivery to mesenchymal stem cells by an ethylenediamine-modified polysaccharide from mulberry leaves. Small. 2012;8(3):441-451.

83. Kofron MD, Laurencin CT. Bone tissue engineering by gene delivery. Adv Drug Deliv Rev. 2006;58(4):555-576.

84. Nie Y, Zhang ZR, He B, Gu Z. Investigation of PEG-PLGA-PEG nanoparticles-based multipolyplexes for IL-18 gene delivery. J Biomater Appl. 2011;26(8):893-916.

85. Elazar V, Adwan H, Bäuerle T, Rohekar K, Golomb G, Berger MR. Sustained delivery and efficacy of polymeric nanoparticles containing osteopontin and bone sialoprotein antisenses in rats with breast cancer bone metastasis. Int J Cancer. 2010;126(7):1749-1760.

86. Dominici M, Le Blanc K, Mueller I, et al. Minimal criteria for defining multipotent mesenchymal stromal cells. The International Society for Cellular Therapy position statement. Cytotherapy. 2006;8(4): 315-317.

87. Pittenger MF, Mackay AM, Beck SC, et al. Multilineage potential of adult human mesenchymal stem cells. Science. 1999;284(5411): 143-147.

88. Wang W, Ferguson DJ, Quinn JM, Simpson AH, Athanasou NA. Biomaterial particle phagocytosis by bone-resorbing osteoclasts. J Bone Joint Surg Br. 1997;79(5):849-856.

89. Kwoh DY, Coffin CC, Lollo CP, et al. Stabilization of poly-L-lysine/ DNA polyplexes for in vivo gene delivery to the liver. Biochim Biophys Acta. 1999;1444(2):171-190.

90. Jiang X, Dausend J, Hafner M, et al. Specific effects of surface amines on polystyrene nanoparticles in their interactions with mesenchymal stem cells. Biomacromolecules. 2010;11(3):748-753.

91. Lorenz MR, Holzapfel V, Musyanovych A, et al. Uptake of functionalized, fluorescent-labeled polymeric particles in different cell lines and stem cells. Biomaterials. 2006;27(14):2820-2828.

92. Jiang X, Musyanovych A, Rocker C, Landfester K, Mailander V, Nienhaus GU. Specific effects of surface carboxyl groups on anionic polystyrene particles in their interactions with mesenchymal stem cells. Nanoscale. 2011;3(5):2028-2035.

93. Tautzenberger A, Lorenz S, Kreja L, et al. Effect of functionalised fluorescence-labelled nanoparticles on mesenchymal stem cell differentiation. Biomaterials. 2010;31(8):2064-2071. 
94. Greulich C, Diendorf J, Gessmann J, et al. Cell type-specific responses of peripheral blood mononuclear cells to silver nanoparticles. Acta Biomater. 2011;7(9):3505-3514.

95. Hackenberg S, Scherzed A, Kessler M, et al. Silver nanoparticles: evaluation of DNA damage, toxicity and functional impairment in human mesenchymal stem cells. Toxicol Lett. 2011;201(1):27-33.

96. Shah BS, Clark PA, Moioli EK, Stroscio MA, Mao JJ. Labeling of mesenchymal stem cells by bioconjugated quantum dots. Nano Lett. 2007;7(10):3071-3079.

97. Hillaireau H, Couvreur P. Nanocarriers' entry into the cell: relevance to drug delivery. Cell Mol Life Sci. 2009;66(17):2873-2896.

98. Buckwalter JA, Glimcher MJ, Cooper RR, Recker R. Bone biology. J Bone Joint Surg Am. 1995;77(8):1256-1275.

99. Cai Y, Liu Y, Yan WQ, et al. Role of hydroxyapatite nanoparticle size in bone cell proliferation. J Mater Chem. 2007;17:3780-3787.

100. Hu Q, Tan Z, Liu Y, et al. Effect of crystallinity of calcium phosphate nanoparticles on adhesion, proliferation, and differentiation of bone marrow mesenchymal stem cells. J Mater Chem. 2007;17: 4690-4698.

101. Liu Y, Wang G, Cai Y, et al. In vitro effects of nanophase hydroxyapatite particles on proliferation and osteogenic differentiation of bone marrow-derived mesenchymal stem cells. J Biomed Mater Res A. 2008;90(4):1083-1091.

102. Okafor CC, Haleem-Smith H, Laqueriere P, Manner PA, Tuan RS. Particulate endocytosis mediates biological responses of human mesenchymal stem cells to titanium wear debris. J Orthop Res. 2006;24(3):461-473.

103. Zeller A, Musyanovych A, Kappl M, et al. Nanostructured coatings by adhesion of phosphonated polystyrene particles onto titanium surface for implant material applications. ACS Appl Mater Interfaces. 2010;2(8):2421-2428.

104. Chung TH, Wu SH, Yao M, et al. The effect of surface charge on the uptake and biological function of mesoporous silica nanoparticles in 3T3-L1 cells and human mesenchymal stem cells. Biomaterials. 2007;28(19):2959-2966.

105. Hsiao JK, Tsai CP, Chung TH, et al. Mesoporous silica nanoparticles as a delivery system of gadolinium for effective human stem cell tracking. Small. 2008;4(9):1445-1452.

106. Mailänder V, Lorenz MR, Holzapfel V, et al. Carboxylated superparamagnetic iron oxide particles label cells intracellularly without transfection agents. Mol Imaging Biol. 2008;10(3):138-146.

107. Gao L, Zhuang J, Nie L, et al. Intrinsic peroxidase-like activity of ferromagnetic nanoparticles. Nat Nanotechnol. 2007;2(9):577-583.

108. Huang DM, Hsiao JK, Chen YC, et al. The promotion of human mesenchymal stem cell proliferation by superparamagnetic iron oxide nanoparticles. Biomaterials. 2009;30(22):3645-3651.

109. Lohmann CH, Schwartz Z, Koster G, et al. Phagocytosis of wear debris by osteoblasts affects differentiation and local factor production in a manner dependent on particle composition. Biomaterials. 2000; 21(6):551-561.

110. Hsieh MF, Li JK, Lin CA, et al. Tracking of cellular uptake of hydrophilic $\mathrm{CdSe} / \mathrm{ZnS}$ quantum dots/hydroxyapatite composites nanoparticles in MC3T3-E1 osteoblast cells. J Nanosci Nanotechnol. 2009;9(4):2758-2762.

111. Schmidt SM, Moran KA, Tweed Kent AM, et al. Uptake of calcium phosphate nanoshells by osteoblasts and their effect on growth and differentiation. J Biomed Mater Res A. 2008;87(2):418-428.

112. Tautzenberger A, Kreja L, Zeller A, et al. Direct and indirect effects of functionalised fluorescence-labelled nanoparticles on human osteoclast formation and activity. Biomaterials. 2011;32(6):1706-1714.

113. Chen L, McCrate JM, Lee JC, Li H. The role of surface charge on the uptake and biocompatibility of hydroxyapatite nanoparticles with osteoblast cells. Nanotechnology. 2011;22(10):105708.

114. Nair S, Sasidharan A, Divya Rani VV, Menon D, Manzoor K, Raina S. Role of size scale of $\mathrm{ZnO}$ nanoparticles and microparticles on toxicity toward bacteria and osteoblast cancer cells. J Mater Sci Mater Med. 2009;20 Supp1 1:S235-S241.
115. Xu JL, Khor KA, Sui JJ, Zhang JH, Chen WN. Protein expression profiles in osteoblasts in response to differentially shaped hydroxyapatite nanoparticles. Biomaterials. 2009;30(29):5385-5391.

116. Zhang Y, Yu W, Jiang X, Lv K, Sun S, Zhang F. Analysis of the cytotoxicity of differentially sized titanium dioxide nanoparticles in murine MC3T3-E1 preosteoblasts. J Mater Sci Mater Med. 2011;22(8):1933-1945.

117. Shi Z, Huang X, Cai Y, Tang R, Yang D. Size effect of hydroxyapatite nanoparticles on proliferation and apoptosis of osteoblast-like cells. Acta Biomater. 2009;5(1):338-345.

118. Bellows CG, Aubin JE, Heersche JN. Initiation and progression of mineralization of bone nodules formed in vitro: the role of alkaline phosphatase and organic phosphate. Bone Miner. 1991;14(1):27-40.

119. Albers CE, Hofstetter W, Siebenrock KA, Landmann R, Klenke FM. In vitro cytotoxicity of silver nanoparticles on osteoblasts and osteoclasts at antibacterial concentrations. Nanotoxicology. October 21, 2011. [Epub ahead of print.]

120. Capuccini C, Torricelli P, Boanini E, Gazzano M, Giardino R, Bigi A. Interaction of Sr-doped hydroxyapatite nanocrystals with osteoclast and osteoblast-like cells. J Biomed Mater Res A. 2009;89(3):594-600.

121. Colon G, Ward BC, Webster TJ. Increased osteoblast and decreased Staphylococcus epidermidis functions on nanophase $\mathrm{ZnO}$ and $\mathrm{TiO} 2$. J Biomed Mater Res A. 2006;78(3):595-604.

122. Tran N, Webster TJ. Increased osteoblast functions in the presence of hydroxyapatite-coated iron oxide nanoparticles. Acta Biomater. 2011; 7(3):1298-1306.

123. Atkins GJ, Welldon KJ, Holding CA, Haynes DR, Howie DW, Findlay DM. The induction of a catabolic phenotype in human primary osteoblasts and osteocytes by polyethylene particles. Biomaterials. 2009;30(22):3672-3681.

124. Sycheva LP, Zhurkov VS, Iurchenko VV, et al. Investigation of genotoxic and cytotoxic effects of micro- and nanosized titanium dioxide in six organs of mice in vivo. Mutat Res. 2011;726(1):8-14.

125. Schouten C, Meijer GJ, van den Beucken JJ, et al. In vivo bone response and mechanical evaluation of electrosprayed $\mathrm{CaP}$ nanoparticle coatings using the iliac crest of goats as an implantation model. Acta Biomater. 2010;6(6):2227-2236.

126. Jensen T, Jakobsen T, Baas J, et al. Hydroxyapatite nanoparticles in poly-D,L-lactic acid coatings on porous titanium implants conducts bone formation. J Biomed Mater Res A. 2010;95(3):665-672.

127. Yavropoulou MP, Yovos JG. Osteoclastogenesis - current knowledge and future perspectives. J Musculoskelet Neuronal Interact. 2008; 8(3):204-216.

128. Aderem A, Underhill DM. Mechanisms of phagocytosis in macrophages. Annu Rev Immunol. 1999;17:593-623.

129. Beil FT, Barvencik F, Gebauer M, et al. Effects of estrogen on fracture healing in mice. J Trauma. 2010;69(5):1259-1265.

130. MacQuarrie RA, Fang Chen Y, Coles C, Anderson GI. Wear particleinduced osteoclast osteolysis: the role of particulates and mechanical strain. J Biomed Mater Res A. 2004;69(1):104-112.

131. Neale SD, Haynes DR, Howie DW, Murray DW, Athanasou NA. The effect of particle phagocytosis and metallic wear particles on osteoclast formation and bone resorption in vitro. J Arthroplasty. 2000; 15(5):654-662.

132. Greenfield EM, Bi Y, Ragab AA, Goldberg VM, Van De Motter RR. The role of osteoclast differentiation in aseptic loosening. J Orthop Res. 2002;20(1):1-8

133. Settles M, Etzrodt M, Kosanke K, et al. Different capacity of monocyte subsets to phagocytose iron-oxide nanoparticles. PLoS One. 2011;6(10):e25197.

134. Motskin M, Muller KH, Genoud C, Monteith AG, Skepper JN. The sequestration of hydroxyapatite nanoparticles by human monocyte-macrophages in a compartment that allows free diffusion with the extracellular environment. Biomaterials. 2011;32(35): 9470-9482.

135. Väänänen HK, Laitala-Leinonen T. Osteoclast lineage and function. Arch Biochem Biophys. 2008;473(2):132-138. 
136. Beck GR Jr, Ha SW, Camalier CE, et al. Bioactive silica-based nanoparticles stimulate bone-forming osteoblasts, suppress boneresorbing osteoclasts, and enhance bone mineral density in vivo. Nanomedicine. November 15, 2011. [Epub ahead of print.]

137. Sommer B, Felix R, Sprecher C, Leunig M, Ganz R, Hofstetter W. Wear particles and surface topographies are modulators of osteoclastogenesis in vitro. J Biomed Mater Res A. 2005;72(1):67-76.

138. Sul OJ, Kim JC, Kyung TW, et al. Gold nanoparticles inhibited the receptor activator of nuclear factor-kappab ligand (RANKL)-induced osteoclast formation by acting as an antioxidant. Biosci Biotechnol Biochem. 2010;74(11):2209-2213.

139. Nabeshi H, Yoshikawa T, Akase T, et al. Effect of amorphous silica nanoparticles on in vitro RANKL-induced osteoclast differentiation in murine macrophages. Nanoscale Res Lett. 2011;6(1):464.

140. Pal N, Quah B, Smith PN, Gladkis LL, Timmers H, Li RW. Nano-osteoimmunology as an important consideration in the design of future implants. Acta Biomater. 2011;7(7):2926-2934.

141. Cadosch D, Chan E, Gautschi OP, Meagher J, Zellweger R, Filgueira L. Titanium IV ions induced human osteoclast differentiation and enhanced bone resorption in vitro. J Biomed Mater Res. 2009;91(1):29-36.
142. Hirayama T, Fujikawa Y, Itonaga I, Torisu T. Effect of particle size on macrophage-osteoclast differentiation in vitro. J Orthop Sci. 2001;6(1):53-58.

143. Cobelli N, Scharf B, Crisi GM, Hardin J, Santambrogio L. Mediators of the inflammatory response to joint replacement devices. Nat Rev Rheumatol. 2011;7(10):600-608.

144. Kaufman AM, Alabre CI, Rubash HE, Shanbhag AS. Human macrophage response to UHMWPE, TiAlV, $\mathrm{CoCr}$, and alumina particles: analysis of multiple cytokines using protein arrays. J Biomed Mater Res. 2008;84(2):464-474.

145. Liu Y, Chen Z, Gu N, Wang J. Effects of DMSA-coated $\mathrm{Fe}_{3} \mathrm{O}_{4}$ magnetic nanoparticles on global gene expression of mouse macrophage RAW264.7 cells. Toxicol Lett. 2011;205(2):130-139.

146. Sun J, Ding T. p53 reaction to apoptosis induced by hydroxyapatite nanoparticles in rat macrophages. J Biomed Mater Res A. 2009;88(3) 673-679.
International Journal of Nanomedicine

\section{Publish your work in this journal}

The International Journal of Nanomedicine is an international, peerreviewed journal focusing on the application of nanotechnology in diagnostics, therapeutics, and drug delivery systems throughout the biomedical field. This journal is indexed on PubMed Central,

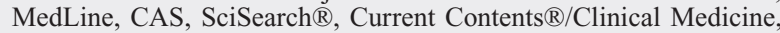

\section{Dovepress}

Journal Citation Reports/Science Edition, EMBase, Scopus and the Elsevier Bibliographic databases. The manuscript management system is completely online and includes a very quick and fair peer-review system, which is all easy to use. Visit http://www.dovepress.com/ testimonials.php to read real quotes from published authors. 